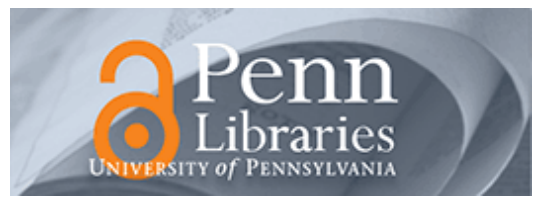

University of Pennsylvania

ScholarlyCommons

Management Papers

Wharton Faculty Research

1994

\title{
Co-Evolution of Capabilities and Industry: The Evolution of Mutual Fund Processing
}

Daniel A. Levinthal

University of Pennsylvania

Jennifer Myatt

Follow this and additional works at: https://repository.upenn.edu/mgmt_papers

Part of the Business Administration, Management, and Operations Commons

\section{Recommended Citation}

Levinthal, D. A., \& Myatt, J. (1994). Co-Evolution of Capabilities and Industry: The Evolution of Mutual Fund Processing. Strategic Management Journal, 15(S1), 45-62. http://dx.doi.org/10.1002/smj.4250150905

This paper is posted at ScholarlyCommons. https://repository.upenn.edu/mgmt_papers/27

For more information, please contact repository@pobox.upenn.edu. 


\title{
Co-Evolution of Capabilities and Industry: The Evolution of Mutual Fund Processing
}

\begin{abstract}
The resource view of the firm has made substantial progress in identifying what attributes of a firm may provide a source of competitive advantage; however, the literature has far less to say about the emergence of these distinctive capabilities. We develop a simple framework based on the role of positive feedback effects of market activity, organizational factors that cause a firm to focus on a particular capability trajectory, and lastly the role of managerial choice with respect to anticipated feedback effects, which we term feedforward effects. We apply this framework to the emergence of competitive positions in the mutual fund-processing business from its inception to 1984 .
\end{abstract}

\section{Keywords}

organizational capabilities, mutual funds

\section{Disciplines}

Business Administration, Management, and Operations 


\section{THE WHARTON FINANCIAL INSTITUTIONS CENTER}

The Wharton Financial Institutions Center provides a multi-disciplinary research approach to the problems and opportunities facing the financial services industry in its search for competitive excellence. The Center's research focuses on the issues related to managing risk at the firm level as well as ways to improve productivity and performance.

The Center fosters the development of a community of faculty, visiting scholars and $\mathrm{Ph} . \mathrm{D}$. candidates whose research interests complement and support the mission of the Center. The Center works closely with industry executives and practitioners to ensure that its research is informed by the operating realities and competitive demands facing industry participants as they pursue competitive excellence.

Copies of the working papers summarized here are available from the Center. If you would like to learn more about the Center or become a member of our research community, please let us know of your interest.

Anthony M. Santomero

Director

The Working Paper Series is made possible by a generous grant from the Alfred P. Sloan Foundation 



\section{Wharton}

Co-Evolution of Capabilities and Industry: The Evolution of Mutual Fund Processing

Working Paper 94-30

Daniel Levinthal Jennifer Myatt 


\title{
Co-Evolution of Capabilities and Industry: The Evolution of Mutual Fund Processing of Financial ${ }^{1}$
}

\begin{abstract}
The resource view of the firm has made substantial progress in identifying what attributes of a firm may provide a source of competitive advantage; however, the literature has far less to say about the emergence of these distinctive capabilities. We develop a simple framework based on the role of positive feedback effects of market activity, organizational factors that cause a firm to focus on a particular capability trajectory, and lastly the role managerial choice with respect to anticipated feedback effects, which we term feedforward effects. We apply this framework to the emergence of competitive positions in the mutual fund processing business from its inception to 1984 .
\end{abstract}

Daniel A. Levinthal, The Wharton School, University of Pennsylvania

Jennifer Myatt, The Wharton School, University of Pennsylvania

This research has been supported by a Sloan Foundation Grant to the Financial Institutions Center at the Wharton School and the Sol C. Snyder Entrepreneurial Center also at the Wharton School. We gratefully acknowledge the time several participants in the industry took to enrich our understanding of the industry. In particular, we would like to acknowledge Barbara Weidlich of State Street Bank and Dushyant Pandit of PNC Financial Services. We thank Ed Zajac for comments of a prior draft. 
The field of Strategic Management, or Business Policy as it was termed in its early incarnations, has had as a primary mission the analysis of diversity. In early work, the focus was on distinctive competencies among organizations (Selznick, 1957; Andrews, 1971). As the field began to relabel itself Strategic Management, the primary interest became diversity across industries (Porter, 1980). The movement to the industry level of analysis resulted from the successful application of the techniques of industrial organization economics to questions of competitive strategy (Porter, 1980). The recent movement back to the firm-level of analysis seems to have been driven more by empirical anomalies and challenges to management practice than the "technological opportunity" represented by a set of powerful analytical techniques.

In many industries, global competition has increased the number of players in a given product market and thereby reduced the importance of strategic (in the game theoretic sense of the word) behavior. For instance, in the 1950s the automobile industry was fertile ground for examining price collusion (Bresnahan, 1987), while current analysis of the industry focuses on variation in manufacturing systems (Womack, Jones, and Ross, 1990) and product development. (Clark and Fujimoto, 1991). Empirical research regarding the modest returns to diversification efforts (Rumelt, 1974; Porter, 1987) provides some indirect evidence that the choice of industry may be less critical to firm performance than the presence of distinctive capabilities to operate within a given industry. Rumelt's (1991) efforts at disentangling business unit effects from corporate and industry effects provides more direct evidence of this.

This shift to a firm-level of analysis on the part of researchers has engendered tremendous excitement in the research literature (Barney, 1991) and has had a profound impact on the discourse of practitioners whose conversations are now replete with words such as core 
competence and capabilities. In assessing this emerging research stream, which generally goes under the label the resource view of the firm, there appears to have been substantial progress in identifying what attributes of an firm may provide a source of competitive advantage (Barney, 1991) as well as significant insight as to the sustainability of these advantages (Ghemawat, 1986; Rumelt, 1984). However, as Foss, Knudsen, and Montgomery (1993) note, the characterizations of what constitutes a valuable resource or capability tends to be ex-post. The literature has far less to say about the emergence of these distinctive capabilities. There is also a sense that the ebb and flow of strategy research may have swung excessively to firm centered analyses and has tended to ignore industry dynamics (Levinthal, 1994 forthcoming).

The present paper is an effort to make some modest progress toward redressing these two weaknesses in the literature on firm capabilities. We consider these issues from the perspective of evolutionary systems, in particular emphasizing the role of positive feedback effects (Arthur, 1990). Positive feedback effects reinforce a process in its current trajectory. Arthur (1989) has applied these notions to understand the role of installed base of users on competition among alternative technological standards. We explore the implications of positive feedback of market activity on capability formation. Some of these are relation-specific, that is within a particular customer-supplier pair, while others are more diffuse and result from overall market activity. We also consider the organizational factors that influence the degree to which a firm might pursue a given set of opportunities. In addition to recognizing these organizational resources and constraints, managers make choices concerning resource allocation and market initiatives based on anticipated feedback effects. We term such considerations feedforward effects. This approach allows us to address both the issue of the emergence of diversity among firms, as well 
as allow us to examine the coupling between industry-level forces and these firm-level dynamics. We apply this conceptual framework to the development of the mutual fund processing industry.

\section{Co-Evolution of Capabilities and Industry $^{1}$}

How a firm's capabilities evolve is intimately linked with how the markets a firm serves evolve. This coupling is not merely the result of financial flows derived from profitable markets providing the basis for investment resources. There are clearly instances in which such a coupling is important, but the presence of well developed capital markets in Western economies tends to mitigate the importance of purely financial couplings. More importantly, many organizational capabilities emerge, are refined, or decay as a result of, or an absence of, product market activity. Therefore, the particular submarkets a firm serves will engender a distinctive, though not necessarily unique, set of capabilities. Certainly, many capabilities, particularly research activity, do not follow directly from current operations. However, even with regard to such investments, the incentives that a firm has to make such investments and the political forces internal: to the firm that may influence such decisions are not independent of its current product market activities.

The fate of a firm's capabilities, however, is not purely a deterministic outcome of such couplings. Indeed, the couplings themselves are a critical management decision. What markets should the firm serve? What activities should be performed within the firm and what sorts of external linkages should the firm make? These choices provide managerial discretion over the evolutionary path that the firm's capability set takes. The framework suggested here is

${ }^{1}$ The material in this subsection draws upon Levinthal (1994, forthcoming). 
somewhat akin to the distinction Argyis and Schon (1978) make between first-order and secondorder leaming processes. The impact on capabilities of serving particular markets is analogous to a first-order learning process. :While not automatic, first-order leaming processes are a direct outcome of the existing structure. By establishing a new set of linkages, whether by choice of a new submarket to serve, a new set of customer relations, or a new internal organizational structure, management sets in imotion a new direction for the development of the firm's capabilities.

Feedback

Feedback effects can greatly amplify the existing heterogeneity in a population of organizations. Perhaps the most prominent example of such feedback effects in the strategy literature revolve around the re-enforcing advantages of market position (Rumelt, 1984). In particular, the notion of a learning or experience curve implies that greater market share will lead to lower costs, which in turn will tend to enhance the firm's market share (Boston Consulting Group, 1972). The notion of absorptive capacity (Cohen and Levinthal, 1989 and 1990) has a similar implication: Organizations with more expertise in a particular technical domain will more readily acquire subsequent knowledge in that domain. Market position advantages associated with a firm's scale of operations may also be self-reinforcing. As Cohen and Klepper (1992) argue in the context of firms' investment in research and development activity, the ability of firms to appropriate the returns to such investments is often a function of their existing sales base.

The notion of brand equity (Aaker, 1991) offers another illustration of such market 
position advantages. Not only does a strong brand name enhance the margins a firm receives on a particular product, but the ability of a firm to place that brandname on other related products enhances the ability of the firm to extend its product line. In addition, the introduction of these product extensions which share the established name result in an higher level of brand awareness, further enhancing the brand equity. Of course the fungibility of brandname is not boundless and, indeed, extensions of brandnames to inappropriate domains may negate their value.

An important caveat to these market positional advantages is that they are self-reinforcing in competitive environments in which the bases of competitive advantage are stable. Conversely, in changing environments, these same self-reinforcing mechanisms may lead to a decline in a firm's competitive position (Levinthal, 1992). The needs of existing customers may change or the subfields and customers that the firm serves may decline. More basic changes such as the technology underlying an industry or the regulatory structure may disrupt the drivers of success (Abernathy and Clark, 1985).

Indeed, feedback effects may reduce the likelihood that a firm will successfully adapt to such changes. For instance, an established firm may have more incentive to invest in incremental changes in a current technology than in exploring more radical innovations. More generally, Levinthal and March (1993) argue that myopia tends to be an important property of many organizational learning processes. The returns to exploiting existing knowledge and capabilities tend to be more certain and immediate than the returns to the exploitation of novel capabilities and opportunities. Furthermore, the past exploitation activities in a given domain tend to make further exploitation in that domain even more attractive due to various sorts of 
competency learning. This positive reinforcement of activities in the current domain in which returns are relatively certain and favorable tends to drive out search for alternative bases of action. $^{2}$

\section{Initial Conditions}

Feedback effects influence a firm's capabilities within the context of an ongoing relationship. However, when a firm enters a product area or new exchange relationship, its capabilities are heavily influenced by its prior activities. Such feedback effects that precede the current market activity will be referred to as initial conditions. While a number of initial condition are specific to a particular firm, such as its bundle of co-specialized assets (Teece, 1986), others, such as geographic effects, influence a broad set of firms.

Geographic effects on firms' competitiveness have been a recent source of inquiry in the economics and strategy literatures (Arthur, 1986; Krugman, 1991; Porter, 1990). Krugman draws on Marshall's (1920) arguments regarding non-pecuniary externalities. Contiguous location of firms within the same industry or that draw on similar skills allow firms to take advantage of a pool of workers with specialized skills. More generally, an infrastructure of physical systems, specialized supporting organizations, as well as skilled workers, develops. In addition, the contiguous location of the firms enhances their ability to learn from each other (Enright, 1993).

${ }^{2}$ Christensen and Bower (1994) provide a compelling example of this phenomenon in the context of the disk drive industry. Strong existing customer relations provide an incentive to advance the existing technological trajectory; however, when new technological opportunities do not correspond to current customer needs they tend not to be pursued. 
Many initial conditions are specific to a firm. Fichman and Levinthal (1991) characterize a wide variety of "assets" that an organization may have even at its founding. For instance, organizations may have pre-existing ties to customers. Alternatively, the founders themselves may bring with them important skills and industry expertise. Few firms enter a new industry subfield with a clean slate (Mitchell, 1989). The vast majority of entrants possess some existing base of capabilities. These capabilities may have been developed through firm operations in other markets, but even new firms inherit capabilities from the previous experiences of the firm's founders.

\section{Feedforward}

The prior section characterizes some ways in which heterogeneity among firms may become amplified over time. Prescient managers appear to recognize such feedback effects in making decisions about what industries or emerging subfields to enter and which clients may help further the firm's development. Thus, in making a choice about what markets to serve, a firm is making a bet on a co-evolutionary process. The firm is, or should, not only be concerned about its current capability to compete within that domain, but also with how participating in that particular industry or subfield will effect the firm's future capabilities.

Perhaps the most basic attribute of the markets and customers served that will impact the development of the firm's capabilities is their growth rate. Is the firm serving customers and market segments that are growing rapidly and thereby can provide a rich experience base for the firm. In addition, leading edge customers may expose the firm to advances in technology (Von Hippel, 1988) and product offerings. 
For instance, consider a firm that wishes to participate in the mutual fund industry. One of the critical choices that such a firm most make is its mode of distribution. Will the firm rely on direct sales or selling through a financial intermediary such as a bank or independent financial agents. The firm's choice of distribution system may set it on a virtuous or destructive coevolutionary process. The firm must both assess the overall market penetration of that particular mode of distribution and the feedback effects of serving that sub-market.

Similarly, consider the co-evolution of a firm's capabilities and industry when the industry is in decline. As markets shrink, so does re-investment in equipment. This yields a vintage effect on the firm's production capabilities. Indirectly, this has further implications for a firm's technical capabilities. For instance, top flight engineers value being able to work on the latest equipment and the associated technical challenges; therefore, as the equipment begins to become dated the firm begins to lose some of its most valuable engineering talent.

Certain subfields impose greater or fewer technical demands on a firm than others. For instance, in printed circuit boards if a firm only participates in the defense sector, it will not develop the technical competence to deal with the high density requirement of commercial markets. Thus, serving leading commercial markets is a critical means of developing new capabilities within PC Board manufacturing.

Along the same lines, certain customers may drive the firm to enhance their capabilities. For instance, State Street Bank, within the mutual fund industry, has such a large proportion of the market for mutual fund processing that it is likely to experience first any new demand associated with new instruments, such as financial derivatives or new services. In the process of serving this demand for a new service, the firm enhances its capabilities relative to 
competitors. Similarly, R.R. Donnelley, a commercial printing firm which traditionally focused exclusively on the U.S. market, has developed significant foreign operations as it followed its client telecommunication companies overseas (Carey, 1993). In addition, serving the computer industry was the catalyst for Donnely learning about emerging technologies (Carey, 1993).

The role suggested here of leading edge customers is analogous to Porter's (1990) discussion of demand factors associated with industry performance across nations. Porter (1990) points to two critical attributes of home country demand. One is timing. Does the home country tend to be early or late in its demand for a particular class of new products or services. The;second is the level of sophistication and the degree to which customers are demanding in their quality requirements. These factors influence the speed and direction with which organizations proceed along their evolutionary trajectory.

;

\section{Focusing Forces}

: The notion of feedforward suggests a significant role for managerial discretion. By its choice of customers and submarkets, top management has an important role in influencing the evolution of the firm's capability set. These choices about external linkages, however, may be constrained by the internal attributes of the firm. Obviously, the existing capability set determines what external linkages are competitively viable. As Teece, Pisano, and Shuen (1990) suggest in their discussion of dynamic capabilities, there are a variety of focusing forces that tend to constrain a firm to a particular capability trajectory.

: The term learning often carries with it the connotation of an activity or idea being novel. However, learning processes often serve to constrain the range of organizational activities 
(Levinthal and March,. 1993). As noted earlier, rapid leaming may result in a competency trap whereby increasing skiłl at the current procedures make experimentation with alternatives progressively less attractive. Along similar lines, Cohen and Levinthal (1989 and 1990) argue that the ability of firms to evaluate and utilize outside knowledge, what they term absorptive capacity, is a function of their prior related knowledge. As a result, firms will tend to confine themselves to a limited set of technological domains and have difficulty responding to developments outside those areas.

Teece, et al. (1990) point out that the presence of co-specialized assets (Teece, 1986) will also act as a constraining force of the development of firm capabilities. They suggest that complementary or co-specialized assets whose value is enhanced by a particular class of innovative activities will steer the firm's resources in that direction. One can think of this argument in the context of Sutton's (1991) work on the effect of sunk costs on firm and industry development. A pre-existing co-specialized asset is a sunk cost, which then can influence the firm's subsequent investment decisions.

The political structure of a firm represents another important class of constraining forces. There is a large literature in the management field (Hambrick and Finkelstein, 1987; Tushman and Romanelli, 1985) concerned with the role of top management in both inhibiting and facilitating organizational change. A particular form of this argument is that incumbent executives tend to be committed to the company's current course of action. Some variants of this argument are psychological, either associated with psychological commitment (Staw, 1981) or cognitive blinders that restrict the management's awareness of alternative courses of action (Daft and Weick, 1984; Dutton and Dukerich, 1991; Zajac and Bazerman, 1991). Other 
variants revolve around issues of organizational politics either internal to the firm (Boeker, 1989) or external (Zajac and Kraatz, 1993). A switch in strategy may change the importance of particular units of the organization and, thereby, threaten existing power bases. Alternatively, changes in strategy may disrupt external constituencies.

The following figure offers a simple schematic representation of the interplay between organizational processes and industry dynamics in determining the firm's "capability trajectory". Such an open systems perspective is clearly not new. However, as suggested earlier, the strategy field has not been terribly effective at bridging such levels of analysis and perspectives. Subsequent sections of the paper apply this general perspective to the competition among providers of custody and transfer agency services in the mutual fund business. In this context, the ability to sustain market relations and to acquire new ones is quite dependent on a variety of feedback mechanisms from general product market activity, but also importantly a history of relationships between intermediaries, including relationships between processors and funds; and also relationships between processors and both investment managers and distributors, and even geographic location.

Insert Figure 1 about here 


\section{Mutual Fund Industry}

\section{Birth of an Organizational Form}

We explore these ideas of co-evolution of capabilities and industry in the context of the mutual fund industry. The Massachusetts Investment Trust, established in 1924, is usually identified as the first mutual fund. However, investment trusts, organized in Britain to invest in the United States, had existed for more than 100 years by the time that the Massachusetts Investment Trust was started. Massachusetts Investment Trust differentiated itself from these prior trusts through its novel offering structure. Under the traditional trust structure, a group of individuals entrusted their financial assets to a "trustee" who invested the assets as a pool. This type of investment occurred through a private arrangement between the investors and the trustee. Unlike these early trusts, Massachusetts Investment Trust offered participation in a group of investments to the public through an offering of shares. The number of shares available and the time limit of the offering were not fixed. This type of fund came to be known as an open end fund. ${ }^{3}$

One of the main attractions of mutual funds to investors is the degree of liquidity they offer in comparison to other investment vehicles. What distinguishes open-end investment companies is their constant readiness to repurchase or redeem their outstanding shares at the current value. Most of these companies continuously offer new shares as well. Another feature of mutual funds is regular reports concerning the operations and portfolio holdings of their companies and, in particular, the daily reporting of their net asset value (NAV). Due to

${ }^{3}$ In contrast, what become known as closed-end funds, are funds that have a fixed offering of shares. Purchases and redemptions of closed-end funds require a transaction on a stock exchange analogous to the purchase or sale of corporate stock. 
regulatory requirements, funds are required to publicly disclose their asset, income and expense structure annually. In order to qualify for investment company status, mutual funds are also required to distribute substantially all net income from dividends, interest and capital gains directly to investors.

\section{Mutual Fund Functions}

The provision of a mutual fund involves four basic functions: investment management, distribution, custody and fund accounting, and transfer agency or shareholder services. While all these activities underlie the provision of a mutual fund, the mutual fund itself need not provide any of these services. The fund sponsor, however, is responsible for contracting for these services or providing them itself. Mutual fund companies differ according to how each function is accomplished and whether the activity is carried about by the fund complex itself or some independent party. Despite the differences in configuration, each function must be completed in order to offer mutual funds to potential investors.

Investment management, the portfolio decisions regarding the fund's investments, is often carried out by an independent investment advisor but more typically is performed by the mutual fund sponsor itself. This intemal provision of investment decisions may reflect the fact that the rate of return on invested funds is the most basic means by why funds differentiate themselves. A rather different motivation stems from the fact that the provision of investment management services is viewed as the most profitable activity in the mutual fund business. Therefore, keeping this activity in-house tends to be in the interest of the management of the mutual fund.

Funds are offered to investors through two types of distribution channels. 
Investors may buy shares directly from a fund via phone or direct mail marketing. They may also buy shares through a sales force. In the latter case, the underwriters of the fund act as wholesalers and establish sales agreements with various distributors. Several different types of distributors may be contracted by the underwriters, including stock brokers, financial planners, and insurance agents.: Some underwriters employ their own captive sales force. The term captive refers to the fact that the sales force only sells the mutual funds of that particular underwriter, as opposed to brokers who may sell funds offered by several different underwriters. As of $1992,59 \%$ of funds were sold through a sales force and $41 \%$ through direct marketing.

The custodianship, or trust and custody function is responsible for the physical holding of securities in which fund assets are invested. Securities regulations require that this function be handled by a bank. Related to the custody activity is fund accounting and administration. Fund: accounting is responsible for the record keeping of the fund from an investment, rather than shareholder, perspective. This function involves tracking the investment of a fund's assets. Mutual fund regulations require that funds calculate a net asset value on a daily basis. Essentially a simple record keeping function, fund accounting is made more difficult by complex securities including derivatives, junk bonds, among others whose values are not always easily determined. In general, the discipline of same day reconciling of all security trades, as opposed to the five working days allowed for stock transactions, poses significant demands on the processor. While fund accounting is responsible for maintaining the accounting records of the fund, fund administration is responsible for compliance records. As both areas use the same data for their records, they are generally treated as the same function. Fund administration is responsible for reporting to the SEC and other regulatory agencies and the fund 
board of trustees regarding fund activities.

Transfer agency is the function responsible for maintaining records of shareholder transactions. Accounting books are kept on the shares held by individuals. The information is then used to generate shareholder reports. This function becomes more complex in fund sponsors that offer the same fund under different fee structures, where the differences in fee structures typically reflect different modes of distribution. The transfer agency function is also responsible for keeping track of the amount of money invested in the fund, which is important from an investment management perspective, to ensure that the fund's assets are fully invested. This function is usually highly mechanized, and as a result is subject to significant economies of scale. In recent years, this function has become labeled shareholder services. This change in labeling reflects an increased emphasis on customer relations, particularly for fund complexes that engage in direct sales to end customers. These funds have developed more extensive customer support in order to compete more effectively with funds that offer customers a broker/dealer as an intermediary. Shareholder service encompasses all activities concerning contact between the shareholder and the fund. Activities include generating and sending shareholder account statements and responding to shareholder inquiries. Larger mutual fund complexes often handle this function internally in order to control the quality of service provided to its customer and to protect client relationships.

Our analysis focuses on those activities that have historically not been provided by the mutual funds themselves. The reason for this is that over the seventy year time span of the mutual fund industry, we can not hope to have measures of efficiency or productivity with respect to the various underlying activities. However, for those activities that are subject to 
market forces, competitive viability should reflect the firm's competence in the given domain. The two activities that fall under this category are custody and transfer agency. Custody is the "cleanest" activity in this regard since, by law, it must be provided by an independent firm. In contrast, transfer agency activity has seen a consider degree of change over the years in the extent to which funds provided this service themselves or contracted externally for the service. Early on in the mutual fund industry, almost all funds relied on an external transfer agent. For instance, in $194089 \%$ of the assets in the industry were managed by an external transfer agent. In the 1970s, there was a movement towards in-sourcing of transfer agency among the larger mutual fund complexes. This movement was driven by both a desire to have more control over their customer relations and a belief on the part of many funds that they had achieved sufficient scale of operations to be efficient in the provision of these services. Many funds, however, latter reversed themselves and again engaged an outside firm to provide these services. As of $1984,66 \%$ of the assets and $57 \%$ of the funds were handled by an outside firm.

\section{Evolution of Fund Processors}

Initial Conditions

Within the mutual fund business, there are a variety of initial conditions that influence a firm's ability to compete. Perhaps most important has been the existing base of investment assets. Early on in the industry, a large pool of investment trust assets provided a basis for the initial capitalization of a fund. More recent years have witnessed a similar phenomenon with respect to retail banks and certificate of deposits. As these certificates mature, banks have tried 
to retain control over the funds by encouraging customers to re-invest in a bank operated mutual fund. Similarly, brokerage houses have successfully entered the mutual fund business by leveraging their existing customer pool. Mutual fund complexes themselves exhibit this pattern when they draw investors to a new fund from their existing accounts.

With regard to processing activities, the fund managers also may have existing business relationships with the processor. The most direct form of these on-going relationships is a situation in which the processor is currently servicing other mutual funds under the control of the same management. Directors of the mutual fund may have other business or even nonbusiness ties to potentiat providers of fund processing services. Indeed, the very first mutual fund, Massachusetts Investment Trust chose State Street Bank as its custodian and transfer agent due to existing relationships between management of the two firms (Wilson, 1949).

We predict that funds which are part of fund complexes that have existing relationships with a given processor will be more likely to choose that processor when they are initiating a new relationship. Futhermore, as a crude proxy for the possible importance of socially embedded relationships (Granovetter, 1985), we examine the importance of geographic location. Co-location of the fund and the processor is weakly suggestive of social embeddedness.

\section{Feedback}

Transfer agency and custody operations, particular in the last two decades, are viewed as scale intensive businesses. In our analysis, we examine the effect of scale, as measured by market share, on both the probability of existing relationships continuing as well as on the likelihood of a fund that is switching processors choosing a given processor. 
Independent of scale effects, one may observe positive feedback in the form of experiential leaming. Again with regard to experience effects, the relevant experience base may be across all funds or a more narrow category. Experience may also be specific to a particular client (Levinthal and Fichman, 1988). Such relationship specific assets may consist of wellgrounded communication patterns and the development of trust among those individuals involved in boundary-spanning jobs (Adams, 1976), knowledge of the peculiarities of a firm's accounting system and products. They may be in the form of skills embodied in people and organizational routines, as well as skills embodied in assets like computer software or special-purpose written procedures (Nelson and Winter, 1982). Whatever their form, as a result of investments by both parties to make the relationship function effectively and of learning over time, the two parties to the exchange develop relation-specific assets. The common feature of these assets, which is central to our analysis, is that they can only emerge over time.

Therefore, we examine the effect of duration of fund-processor relationships on the probability of those relationships continuing. In addition, a fund that is engaging in the choice of a new processor may be part of a fund complex that has on-going relations with a variety of processors. Therefore, we also examine the effect of the duration of these complex level processor relationships on the funds' choice of a new processor.

Fit

These forces of positive feedback may at times be attenuated, and perhaps even prove dysfunctional, as the needs and requirements of clients change. For instance, if a fund changes its mode of distribution then the experiential base of its processor with regard to the prior mode 
of distribution is no longer relevant. With regard to the custody business, an important source of relationship specific may learning occur between the investment manager and the custodian. Therefore, a switch in investment manager may eliminate this relationship specific capital. We examine the impact of a change in investment advisors on the probability of a fund continuing to engage its current custodian. Similarly, we look at the impact of a change in distributor on the persistence of the relationship between the transfer agent and the fund. Moving from one distribution mode to another (ex., captive broker-dealer to non-captive or broker-dealer to direct) changes the demands faced by the transfer agent; furthermore, even moving from one distributor to another within the same mode may disrupt the systems and routines developed by the transfer agent.

\section{Focusing Forces}

In the early days of the mutual fund business, the processing of fund accounts was not viewed as a particularly high growth or profitable business. Therefore, banks that were strong in traditional lines of business may not have aggressively pursued fund processing. Furthermore, financial institutions for which fund processing represents a more substantial portion of their overall business activity may be more likely to aggressively re-invest resources and pursue new opportunities in this area.

We do not have reliable profitability data on custodian banks over the life history of the industry; however, we do have data on the level of assets of these banks. This information on overall assets for the banks allows us to construct a measure of the ratio of mutual fund assets for which the bank serves as custodian to the bank's own assets. This measure provides an 
indication of the intensity of the bank's involvement in the fund's business relative to their overall activity.

Transfer agents may be banks but may, particularly in more recent years, be non-banks that specialize in transaction processing activities. Therefore, the measure of intensity of involvement used in the case of custodians can not be applied. Instead we indicate with a dummy variable whether the transfer agent is a non-bank transaction processor or a banking institution. In a dichotomous way, this measure captures the degree to which the processor is focused on the mutual fund business.

Our preceding argument suggests that the measures of focus should be positively related to the persistence of on-going relationships as well as positively associated with the likelihood of a fund choosing to initiate a relationship with that processor.

The following table summarizes the categories of variables to be considered and indicates the particular measures to be used as well. In addition to these measures, a few control variables were included in the analysis. First, some observers have suggested that relationships between funds and processors have become less stable in recent years. As a result, we include a time period dummy variable to account for the possibility of a shift in the longevity of these relationships. The other control variables are related to the size of the processor and the fund; they are the market share of the particular mutual fund and the market share of the mutual fund complex of which the fund is a part. One might believe that a large fund complex would leverage its bargaining power by playing off service providers on one another over time. Alternatively, larger fund complexes may pose more complex demands on their processors and engender greater opportunities for relation-specific learning (Levinthal and Fichman, 1988). The 
point made here is merely that it may be worth controlling for such effects. In addition, most measures are expressed in relational terms (i.e., market share indicators, relative reliance on a given processor) so that the measures are not distorted by the dramatic growth in the industry over time.

\section{Feedback}

General Expertise

- Overall market share in the processing business

Relationship specific expertise

- $\quad$ Years in the relationship

- $\quad$ Proportion of mutual fund complex assets served by processor

- $\quad$ Proportion of mutual fund complex funds served by processor

- Common geographic setting

\section{Disruptive Forces}

Prior relationship expertise is negated by changes in the structure of the relationship

- $\quad$ Change in investment advisor [custody relationships]

- Change in distributor [transfer agent relationships]

Focus Effects

Indicators of the importance of the fund processing business to the focal firm

- $\quad$ Assets under management relative to total assets [custody business]

- Dummy variable indicating a specialist processor organization versus a bank [transfer agent relationships]

\section{Data}

Data were collected for bond and equity funds from an annual reference put out by Wiesenberger starting in 1934. Wiesenberger provides a variety of information on each fund, including assets under management, information as to the investment manager, transfer agent, and distributor. Since 1965, Wiesenberger explicitly indicates that it profiles all mutual funds 
with at least $\$ 10$ million in assets; the earlier reporting of mutual fund activity appears consistent with this criterion. In cases where the data from Wiesenberger were incomplete, the appropriate years of Moody's Bank and Finance Manual were used. Data on Money Market funds were collected from the IDD Mutual Fund Directory. The IDD Fund Directory attempts to include all money market funds.

From this data on the individual funds, we constructed measures of assets under management for the various transfer agents and custodians in operation during the sample period. Duration data as well were constructed by examining breaks in relationships with a given processor. All breaks in relationships were examined to make sure that there was indeed a change in the relationship and not a change in ownership or name in one of the parties. Data were collected to form a complete census of the population as characterized by the above publications at two year intervals from 1934 to 1984 . While the industry came into being in 1924 with the first open-ended mutual fund, reliable information on service providers was not available until 1934.

\section{Empirical Analysis}

The empirical analysis consists of two basic components. One is a muitinomial logit analysis of the initiation of relationships with a processor and the other is a logit analysis of the probability of an on-going relationship continuing from one period to the next. The significance of a variable or set of variables are assessed with the likelihood ratio test. ${ }^{4}$ The test compares

${ }^{4}$ The likelihood ratio test is preferable to the t-test for assessing the effect of a single variable since tests based on $t$-values of individual coefficients can be misleading in logit analysis (Anderson, et al., 1980). 
the goodness of fit of a pair of nested models, with the variable or variables of interest being the constraints that distinguish the models (Fienberg, 1980). The measure of goodness of fit is the $G^{2}$ statistic; minus two times the value of the log likelihood. Under the null hypothesis, this difference is asymptotically distributed as a chi-squared (Fienberg, 1980). The degrees of freedom for the likelihood ratio test are equal to the number of parameters that distinguish the two models.: The effect of individual variables within each set was assessed by comparing a model excluding the variable of interest with a model containing the full set of variables.

\section{Logit Analysis of Relationship Persistence}

The Logit analysis examines the probability that, from one period to the next, a given relationship will end. Therefore, positive values for an estimated coefficient indicate that for that particular variable an increase in the value of the variable will tend to increase the risk of the relationship ending. Similarly, a negative estimated coefficient indicates that larger values of the variable will tend to be associated with a lower risk of the relationship ending.

The control variables as a set, in contrast to a model consisting of just a constant term, were highly significant $\left(\chi^{2}=11.982, d f=3, p<.01\right)$ in the analysis of switching of transfer agents but did not contribute significantly to the estimation of persistence of custodian relationships $\left(x^{2}=3.197, d f=3, p>.10\right)$. Within the set of control variables for the analysis of transfer agents, the variables for the effect of mutual fund market share $\left(\chi^{2}=6.220, d f=\right.$ $1, p<.05)$ and for the effect of the market share of the mutual fund complex $\left(\chi^{2}=5.955, d f\right.$ $=1, p<.05$ ) were individually significant.

This lack of significance for the control variables in the analysis of custodian 
relationships holds in spite of the fact that there were more observations in the analysis of custodians, 3257 cases versus 1906 cases for the analysis of transfer agents, and a relatively similar total frequency of switching events in the two settings. Out of the 3257 observations of custodian - mutual fund relations, there were 591 switches; similarly, for the 1906 observations of transfer agent - mutual fund relations there were 317 switches. The reason for the greater magnitude of data on custodian - mutual fund relationships is that many mutual fund complexes carry out the transfer agent responsibilities. As our analysis is restricted to market relationships, we are left with a somewhat smaller sample of transfer agent - fund pairs. Along these same lines, it is important to note that we are examining the likelihood of an external transfer agent mutual fund relationship ending in a switch to a new external transfer agent. Other terminating events, such as the closure of the fund or, more commonly, the decision by the fund complex to internalize transfer agent activities, are considering a censoring event and not a switch.

: Insert Table 1 about here

Insert Table 2 about here

Product market activity is strongly self-reinforcing. Processors, whether they are custodians or transfer agents, have a substantially higher probability of continuing their existing customer relationships the larger is their overall market share of assets under management. For 
the case of custodians, the estimate is $\left(\chi^{2}=8.276, d f=1, p<.05\right)$ and for transfer agents $\left(\chi^{2}=12.843, d f=1\right.$, and $\left.p<.001\right)$.

Not only does greater current product market activity tend to lead to greater continuity of existing relationships, but the subsequent multinomial analysis of the choices made by funds initiating a new relationship indicates that greater current market activity has a significant impact of the likelihood of gaining new customers. Obviously, the archival record of business activity in the industry does not give a direction insight as to the source of those scale advantages. While there is clearly a sense in the industry today that scale economies are important, much of that discussion is focused on the distribution of mutual funds and not their processing (Alexander et al., 1994, Makadok, 1992). The major contributor to scale economies in the processing sector of the industry would seem to lie in the large, primarily fixed, costs of software and systems development.

Much of the self-reinforcing feedback stems from particular market relationships. Greater duration of past relations and more extensive ties, either as measured by assets or number of funds within the same mutual fund complex, lead to greater likelihood of a given relationship continuing. In addition, geographic proximity, as measured by the fund and the processor being located in a common state, may facilitate the development of a broader set of ties between the two organizations. In contrast, on-going relationships are threatened if those in important boundary spanning roles depart (Seabright, Levinthal, and Fichman, 1992). Overall, these relational variables are highly significant $\left(\chi^{2}=108.639, d f=5, \mathrm{p}<.001\right.$ for custody relationships and $\chi^{2}=85.69, d f=5, \mathrm{p}<.001$ for transfer agent relationships).

With the exception of the measures of the intensity of the current relationship in the case 
of transfer agents, the various measures of relational feedback are individually significant as well. In the case of transfer agents, both the ratio of the assets of the mutual fund complex that are managed by the processor $\left(\chi^{2}=2.703, d f=1, p>.10\right)$ and the ratio of the number of funds in the overall mutual fund complex managed by the processor $\left(\chi^{2}=1.422, d f=1, p>\right.$ .10) fall a bit short of statistical significance. The measures of the intensity of on-going relationships are significant in the case of custody relationships for both the proportion of funds of the overall mutual fund complex managed by the processor $\left(\chi^{2}=16.591, d f=1, p<.001\right)$ and for the proportion of the assets of the mutual fund complex managed by the processor $\left(x^{2}\right.$ $=3.115, d f=1, p<.10)$.

The duration of the relationship between the fund and processor was individually significant in the case of custody relationships $\left(x^{2}=9.006, p<.01\right)$ and for transfer agents $\left(\chi^{2}=9.530, d f=1, p<.01\right)$. Lastly, geographic proximity has a very strong effect on the persistence of client-firm relationships $\left(\chi^{2}=38.319, p<.001\right.$ for custody and $\chi^{2}=23.487$, $p<.001$ for transfer agents). This effect of geographic location on persistence is independent of the relative concentration of the financial services industry into a few states. The fact that many financial services organizations, both clients and service providers, are located in a few states in and of itself has no obvious implications for the persistence of individual client provider relationships. Indeed, the close proximity of a large number of alternative service providers would seem to enhance the likelihood of such relationships being brief.

To get some idea of the magnitude of these effects, contrast the probability of a mutual fund - processor relationship continuing for two funds which vary according to some of the critical independent variables but share common values for the remaining variables where these 
common values are set at the mean value for the population. First, consider the magnitude of the impact of market share on the persistence of relationships, holding the other variables at their mean value. For custody relationships, a custodian that has 5 percent of the overall market has a probability of .33 of the client ending the relationship over the subsequent two year period, whereas for a custodian with a 25 percent market share the probability is .32 . Thus, despite the strong statistical significance of the market share variable, it has little actual effect on the persistence of these relationships. In contrast, in the case of transfer agent - client relations, there is a greater impact of market share on the persistence of those relationships. A transfer agent with a 5 percent share of the market for external transfer agent services faces a probability of .17 that its client relationship will end by the next time period, while a transfer agent with a market share of 25 percent faces a .14 probability of this happening.

However, the magnitude of the effect of overall market share on the persistence of relationships pales in comparison to the impact of the relational feedback variables. Consider the contrast between a relatively high relational exchange where 75 percent of the mutual fund complex's business (both proportion of funds and assets) is with that processor, the processor and fund operate in the same state, and the processor has been serving the particular fund for 10 years versus a relatively low relational exchange where only 25 percent of the mutual fund complex's business (again, both proportion of funds and assets) is with that processor, the processor is not in the same state, and the processor did not previously serve the client in the prior period. For custody relationships, the probability of the high relational exchange ending is .18 while the probability of the low relational exchange ending is .47 . That is, there is nearly a 50-50 chance that a low relational exchange will end over a two year period. Similarly, for 
transfer agent relationships, the probability of a high relational exchange ending over a two year period is .12 while the probability of a low relational exchange ending is .30 . In contrast to the relatively modest impact of market share on the persistence of relationships, the variation in the intensity of the degree of relational feedback yields impacts on the probability of persistence by a factor of two or more.

Both the switch in advisor in the case of custody relationships $\left(\chi^{2}=30.946, p<.001\right)$ and the switch in distributor $\left(\chi^{2}=3.802, p<.10\right)$ were individually significant. These changes served to disrupt the funds relationships with each external processor, even though the mutual fund not the investment advisor or distributor are responsible for contracting for custody and transfer agent activities. The fact that the change in the identity of these boundary spanning agents reduces the likelihood of the fund - processor relationship continuing is suggestive of the relational nature of these exchanges.

The measure of focus was not associated with the likelihood of the processor relationship continuing in either the case of custodians $\left(\chi^{2}=0.455, d f=1, p>.10\right)$ or for transfer agents $\left(\chi^{2}=2.21, d f=1, p>.10\right)$. The ability to retain clients, while tied to feedback effects at the market level and, more importantly, to feedback effects within on-going relationships, is not influenced by the prominence of the mutual fund business to the processor.

\section{Multinomial Logit Analysis of Processor Choice}

These same constructs were examined in the context of a mutual fund's choice of processor when it is initiating a new processor relationship. The exact same set of variables are not, however, used. First, any variable that does not vary over the alternative set can not be 
included in a multinomial logit. This clearly includes both the time period dummy variable and those variables which are attributes of the mutual funds themselves (i.e., the market share of the fund and the market share of the fund complex). In addition, the relational tie between the processor and mutual fund will vary by processor - fund dyads. Since a given mutual fund complex is going to have on-going relationships with only a small subset of the processors that are active in a given year, this was treated as a dichotomous variable indicating the presence or absence of such a relationship and not as a measure of intensity of the relationship (i.e., proportion of assets and proportion of funds within a complex) as in the case of the logit analysis of the persistence of on-going relationships. Similarly, each fund - potential processor pairing is coded as sharing or not sharing the same geographic location. The remaining variable, the processor's market share, is obviously an attribute of the processor and is independent of the particular potential client mutual fund.

Insert Table 3 about here

Insert Table 4 about here

Relative to a model without covariates, the effect of market share is highly significant in both the case of custody relationships $\left(x^{2}=286.916, d f=1, p<.001\right)$ and for transfer 
agent relationships $\left(\chi^{2}=56.041, d f=1, p<.001\right)$. Furthermore, examining a model in

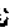

which a market share square term is included, indicates that higher market share resuits in a ; higher probability of engaging a new client over the range of empirically observed market share values. ${ }^{5}$

The three measures of relationship ties collectively have a significant positive effect on the likelihood of a mutual fund choosing a given processor $\left(\chi^{2}=211.19, d f=3, p<.001\right.$ for choice of transfer agent and $\chi^{2}=880.394, d f=3, p<.001$ for custodians). In addition, the three measures are individually significant: $\left(\chi^{2}=143.472, p<.001\right.$ custodian; $\chi^{2}=181.708$, $p<.001$ transfer agent) for the effect of a common state location, $\left(\chi^{2}=22.432, p<.001\right.$ custody; $\chi^{2}=17.821, p<.001$ transfer agent) for the effect of duration of relationship between the overall mutual fund complex and the processor, and $\left(\chi^{2}=548.242, p<.001\right.$ custody; $\chi^{2}=19.071, p<.001$ transfer agent) for the presence of an existing relationship : between the mutual fund complex and the processor. While the focus variables have the predicted sign for both custody and transfer agent relationships, in neither instance is the estimated coefficient statistically significant. For custody relationships the $\chi^{2}$ test yields $\left(\chi^{2}=\right.$ $1.167, p>.10)$ and in the case of transfer agent relationships it yields $\left(\chi^{2}=1.886, p>.10\right)$.

To get some idea of the magnitude of these effects, consider the probability that a given mutual fund would choose a particular processor where processors vary according to their value with respect to some subset of the independent variables in the multinomial analysis and share a common value for the remaining variables, where these common values are set at the mean

${ }^{5}$ The exception to this finding is that there are a few instances in which the maximum value of market share in a given year exceeds the point at which the probability of engaging a new client reaches its maximum value with respect to market share. 
relationships, market share has an enormous impact on the probability that a given fund will initiate a new relationship with a particular processor. In the context of custodian relationships, a custodian with a 5 percent market share has a .03 probability of being chosen by an arbitrary mutual fund while a custodian with a 25 percent market share has a .08 probability of being chosen. Similarly, a transfer agent with a market share of 5 percent has a .04 probability of being chosen by a mutual fund in search of a new service provider, while a transfer agent with a 25 percent market share has a probability of .12 being chosen. Thus, the effect of variation in market share yields difference of two or three orders of magnitude in the likelihood of a relationship being initiated.

The impact of existing relationships between the processor and potential client is even more pronounced. If the mutual fund is part of a fund complex that has an existing relationship with the processor, the likelihood of a relationship being initiated changes by several orders of magnitude: changing from a probability value of .03 to .10 in the case of transfer agent relationships and from .02 to .08 in the case of custody relationships. Surprisingly, the mere fact of being located in the same state has an even larger impact on the likelihood of choosing a processor. For the case of custodians, the probability changes from .01 to .09 and for transfer agents it changes from .01 to .13 .

One might think that this enormous impact of the geographic variable is an artifact of the heavy concentration of financial service activity in a few states. However, this effect is only trivially diminished when a control variable is introduced into the estimating equation that indicates what share of the total processing activity is carried out in the processor's state. The coefficient on the variable indicating a common state changes from 1.732 to 1.710 in the case 
of transfer agents and from 1.624 to 1.618 in the case of custody relationships.

\section{Conclusion}

Heterogeneity in competitive position among firms in the transfer and custody business for mutual funds is influenced by a variety of forces. Some factors, such as market share, amplify the existing heterogeneity. Firms with a strong market position tend to have a higher probability of sustaining on-going relationships and, much more pronounced, a greater tendency to initiate new relationships.

Other factors tend to sustain over time the existing position of firms. Existing relationships are fairly stable. The more extensive the ties between the fund complex and the processor the greater the stability of these relationships. Furthermore, the powerful effect of the geographic variable suggests that these ties do not just consist of narrow task specific knowledge, but may reflect to some extent a more socially embedded relationship (Granovetter, 1985).

Some of these relational factors, such as the effect of duration and intensity of on-going relations, tend to sustain existing competitive positions. However, other relational effects will tend to amplify the existing heterogeneity in the population. Processors that have an existing tie with a mutual fund complex are much more likely to acquire additional funds within that complex as clients. In addition, the analysis is strongly supportive of recent discussion of geographic agglomeration effects (Arthur, 1986; Krugman, 1991).

The lack of significance of the focus variables suggests that the evolution of competitive position is driven by market position and external relationships and that organizational 
commitments and resource allocations do not exert an independent effect on this trajectory. Clearly, however, the current data set is primarily based on measures of market activity and only in a crude way reflects some sense of internal organizational attributes.

Taken as a whole, the empirical evidence offers rather strong support for the arguments regarding amplification of heterogeneity by market activity and the inertial effect on heterogeneity of the relational nature of the exchange relationships. The relative role of these two sorts of forces, however, is clearly context dependent. Financial institutions, by definition, serve an intermediary role and, as a result, client - firm exchanges are likely to have a significant relational component. Contexts will also differ in the degree to which the positive feedback of market activity is enduring over time. The relationships studied here were subject to disruptive forces of changes in the affiliated intermediaries but were not subject to more radical changes in the basis of competitive advantage. Nevertheless, the qualitative distinction between these two sorts of feedback mechanisms, one amplifying heterogeneity and the other sustaining the current level of heterogeneity, is likely to be robust. Heterogeneity in competitive position is sustained by existing market relations and tends to be amplified by overall market position. In these two important respects, the evolution of a given firm's competitive position can be seen as a outcome of linkages to particular clients and the overall market. 


\section{References}

Aaker, David A. (1991). Managing Brand Equity. New York: Free Press.

Abernathy, William J. and Kim B. Clark. (1985). Innovation: Mapping the winds of creative destruction. Research Policy, 14: 3-22.

Adams, S.K. (1976). The structure and dynamics of behavior in organizational boundary roles. In M. Dawned (ed.), Handbook of Organizational and Industrial Psychology.: 1175-1199. Chicago: Rand McNaily.

Aiken M. and J. Hage. (1968). Organizational interdependence and intra-organizational structure. American Sociological Review, 33: 912-930.

Alexander, James, Mark Hurley, Sharon Meers, Yusuf Aliredha and Elizabeth Wang. (1994). The changing economics of the mutual fund industry. Industry Research Group - Goldman Sachs.

Anderson, S., Auquier, A., Hauck, W., Oakes, D., Vandaele, W., and Weisberg, H. (1980). Statistical Methods for Comparative Studies. New York: Wiley.

Andrews, Kenneth R. (1971). The Concept of Corporate Strategy. Homewood, IL: Richard D. Irwin.

Argyris, Chris and Donald Schon. (1978). Organizational Learning. Reading, MA: AddisonWesley.

Arthur, W. Brian. (1986). Industry location patterns and the importance of history. Center for Economic Policy, Stanford University.

Arthur, W. Brian. (1989). Competing technology, increasing returns, and lock-in by historical events. Economic Journal, 97: 116-131.

Arthur, W. Brian. (1990). Positive feedbacks in the economy. Scientific American. 92-99.

Barney, Jay B. (1991). Firm resources and sustained competitive advantage. Journal of Management, 17: 99-120.

Boeker, Warren. (1989). The development and institutionalization of subunit power in organizations. Administrative Science Quarterly, 34: 388-410.

Boston Consulting Group. (1972). Perspectives on Experience. Boston, MA: Boston Consulting Group, Inc. 
Bresnahan, Timothy F. (1987). Competition and collusion in the American automobile industry: The 1955 price war. Journal of Industrial Economics, 35: 457-82.

Carey, Susan. (1993). Donnelley follows its customers around the world. Wall Street Journal. July 1.

Christensen, Clayton M. and Joseph L. Bower (1994) Catching the new wave: Why good customers make it hard. Unpublished manuscript. Graduate School of Business, Harvard University.

Clark, Kim B. and Takahiro Fujimoto. (1991) Product Development Performance: Strategy, Organization, and Management in the World Auto Industry. Boston: Harvard Business School Press.

Cohen, Wesley and Daniel Levinthal. (1989). Innovation and learning: The two faces of R\&D. Economic Journal, 99: 569-596.

Cohen, Wesley and Daniel Levinthal. (1990). Absorptive capacity: A new perspective on learning and innovation. Administrative Science Quarterly, 35: 128-152.

Cohen, Wesley M. and Steven Klepper. (1992). The anatomy of industry r\&d intensity distributions. American Economic Review, 82: 773-799.

Daft, Richard and Karl Weick. (1984). Toward a model of organizations and interpretation systems. Academy of Management Review, 9: 284-296.

Dutton, Jane E. and Janet M. Dukerich. (1991). Keeping an eye on the mirror: Image and Identity in organizational adaptation. Academy of Management Journal, 34: 517-554.

Enright, Michael. (1993). Emerging of technologies: Knowledge-intensive technologies and regional development. Business History Review, 67: 347-349.

Fienberg, Steven E. (1980). The Analysis of Cross-Classified Categorical Data. Cambridge, MA: MIT Press.

Fichman, Michael and Daniel Levinthal. (1991). Honeymoons and the liability of adolescence: a new perspective on duration dependence in social and organizational relationships. Academy of Management of Review, 16: 442-460.

Foss, Nacelle J., Christian Knudsen, and Cynthia A. Montgomery. (1993). Towards a synthesis of evolutionary and resource-based approaches to strategy: Some topics for discussion. Unpublished Working Paper.

Ghemawat, Pankaj. (1986). Sustainable advantage. Harvard Business Review, September- 
October: $53-58$.

Granovetter, Mark. (1985). Economic action and social structure: the problem of embeddedness. American Journal of Sociology, 78: 1360-1380.

Hambrick, Donald and S. Finkelstein. (1987). Managerial discretion: A bridge between polar views of organizational outcomes. In L. L. Cummings and B. M. Staw (Eds.). New Directions in Organizational Behavior: 369-406. Greenwich, CT: JAI Press.

Krugman, Paul. (1991). Geography and Trade. Cambridge, MA: MIT Press.

Levinthal, Daniel A. and Michael Fichman. (1988). Dynamics of interorganizational attachments: auditor-client relations. Administrative Science Quarterly, 33: 345-369.

Levinthal, Daniel A. and James G. March. (1993). The myopia of learning. Strategic Management Journal, 14: 95-112.

Levinthal, Daniel A. (1992). Industrial and Corporate Change, 1: 427-443.

Levinthal, Daniel A. (1994, forthcoming). Strategic Management and the Exploration of Diversity. In Foss, Nacelle J., Christian Knudsen, and Cynthia A. Montgomery (Eds.). Evolutionary and Resource-Based Approaches to Strategy. Orwell, MA: Kluwer Academic Publishers.

Makadok, Richard. (1992). The "winner's competitive cycle" in the money market mutual fund industry: the dynamics of the competitive engine. Unpublished manuseript. Wharton School, University of Pennsylvania.

Marshall, Alfred. (1920). Principles of Economics. London, Macmillan.

Mitchell, Will. (1989). Whether and when? Probability and timing of incumbents' entry into emerging subfields. Administrative Science Quarterly, 34: 208-230.

Moody's Bank and Finance Manual. New York, Moody's Publishing.

Mutual Fund Directory. New York, Investment Dealers' Digest.

Nelson, Richard and Sidney Winter. (1982). An Evolutionary Theory of Economic Change. Cambridge, MA:Harvard University Press.

Porter, Michael E. (1980). Competitive Strategy: Techniques for Analyzing Industries and Competitors. New York: The Free Press.

Porter, Michael E. (1987). From competitive advantage to corporate strategy. Harvard 
Business Review, May-June.

Porter, Michael E. (1990). The Competitive Advantage of Nations. New York: The Free Press.

Rumelt, Richard P. (1974). Strategy, Structure, and Economic Performance. Cambridge, MA: Harvard Business School Press.

Rumelt, Richard P. (1984). Towards a Strategic Theory of the Firm. In Competitive Strategic Management, ed. R. B. Lamb, pp 566-70. Englewood Cliffs, NJ: Prentice-Hall.

Rumelt, Richard P. (1991). How Much Does Industry Matter. Strategic Management Joumal, 12: $167-185$.

Seabright, Mark, Daniel Levinthal and Mark Fichman. (1992). Role of individual attachments in the dissolution of interorganizational relationships. Academy of Management Journal, 35: 122160.

Selznick, Philip. (1957). Leadership and Administration. Harper \& Row: New York.

Staw, Barry M. (1981). The escalation of commitment: A review and analysis. Academy of Management Review, 6: 577-587.

Sutton, John. (1991). Sunk Costs and Market Structure. MIT Press: Cambridge, MA.

Teece, David. (1986). Profiting from technological innovation: Implications for integration, collaboration, licensing, and public policy. Research Policy, 15: 285-305.

Teece, David, Gary Pisano and A. Shuen. (1990). Firm capabilities; resources, and the concept of strategy. Consortium on Competitiveness \& Cooperation Working Paper No. 90-8, University of California at Berkeley.

Tushman, Michael and Elaine Romanelli. (1985). Organizational evolution: A metamorphosis model of convergence and reorientation, in L. Cummings and B. Staw (Eds.), Research in Organizational Behavior, 7: 171-222.

Van de Ven, Andrew H. and G. Walker. (1984). The dynamics of interorganizational coordination. Administrative Science Quarterly, 29: 598-621.

von Hippel, Eric. (1988). The Sources of Innovation. New York: Oxford University Press.

Wiesenberger, A. Investment Companies. Wiesenberger.

Wilson, Julia A. (1949). A Story of Progress. Boston, MA: Massachusetts Investment Trust. 
Zajac, Edward and Max Bazerman. (1991). Blind spots in industry and competitor analysis: Impact of information (mis)perception for strategic decisions. Academy of Management Review, 16: $37-56$.

Zajac, Edward and Matthew Kraatz. (1993). A diametric forces model of strategic change: Assessing the antecedents and consequences of restructuring in the higher education industry. Strategic Management Journal, 14: 83-102. 


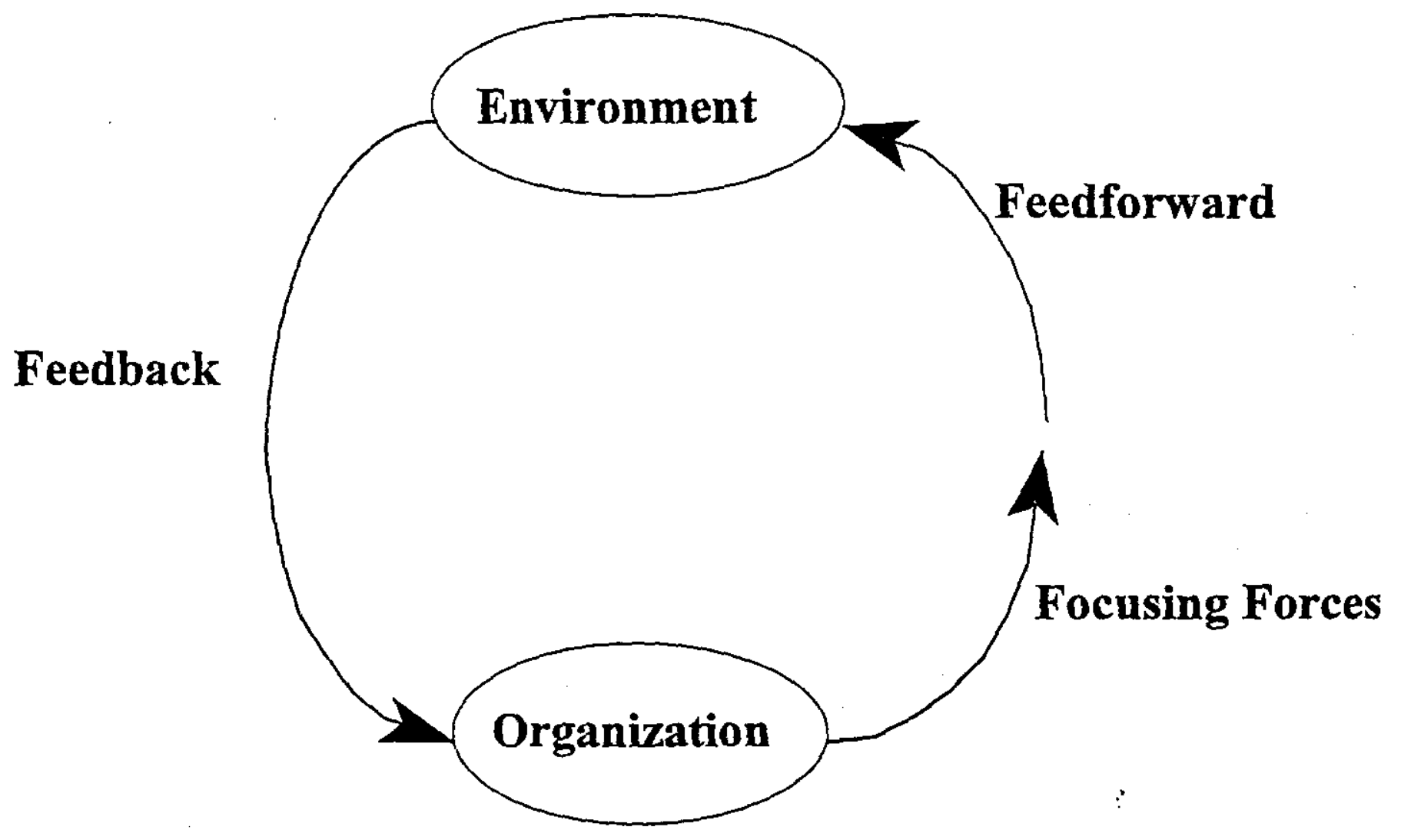

Figure 1: Co-Evolution of Firm and Industry 
Table 1

Logistic Analysis of Custodian Relationships

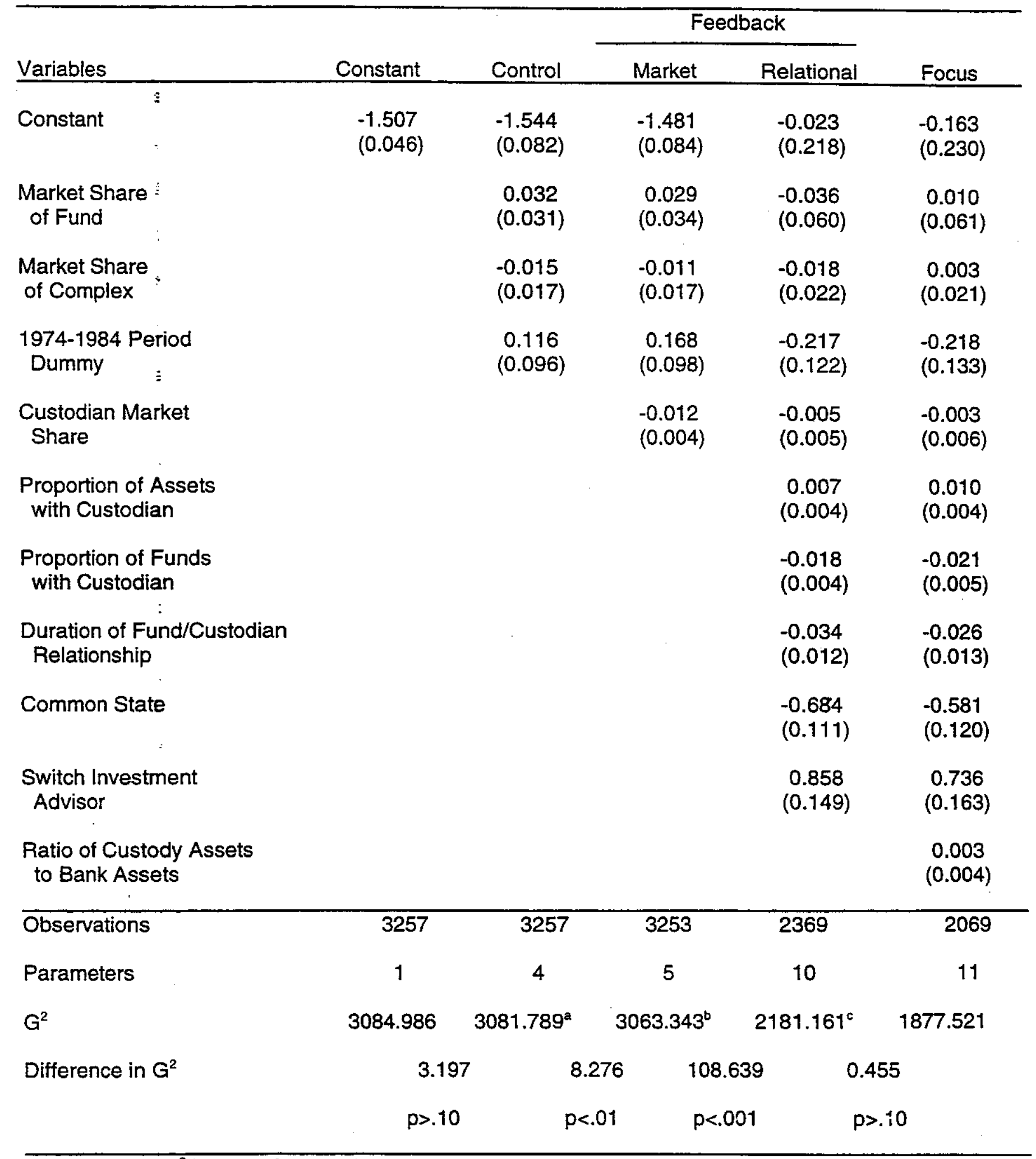

${ }^{a}$ The value of $\mathrm{G}^{2}$ for a $\mathrm{N}$ of 3253 observations is 3071.619

'The value of $G^{2}$ for a $N$ of 2369 observations is 2280.800

'The value of $\mathrm{G}^{2}$ for a $\mathrm{N}$ of 2069 observations is 1877.976 
Table 2

Logistic Analysis of Transfer Agent Relationships

\begin{tabular}{|c|c|c|c|c|c|}
\hline \multirow[b]{2}{*}{ Variables } & \multirow[b]{2}{*}{ Constant } & \multirow[b]{2}{*}{ Control } & \multicolumn{2}{|c|}{ Feedback } & \multirow[b]{2}{*}{ Focus } \\
\hline & & & Market & Relational & \\
\hline Constant & $\begin{array}{l}-1.612 \\
(0.062)\end{array}$ & $\begin{array}{l}-1.618 \\
(0.107)\end{array}$ & $\begin{array}{l}-1.467 \\
(0.114)\end{array}$ & $\begin{array}{l}-0.736 \\
(0.327)\end{array}$ & $\begin{array}{l}-0.675 \\
\langle 0.331\rangle\end{array}$ \\
\hline $\begin{array}{l}\text { Market Share } \\
\text { of Fund }\end{array}$ & & $\begin{array}{c}0.092 \\
(0.036)\end{array}$ & $\begin{array}{c}0.134 \\
(0.038)\end{array}$ & $\begin{array}{c}0.113 \\
(0.049)\end{array}$ & $\begin{array}{c}0.116 \\
(0.049)\end{array}$ \\
\hline $\begin{array}{l}\text { Market Share } \\
\text { of Complex }\end{array}$ & & $\begin{array}{l}-0.061 \\
(0.027)\end{array}$ & $\begin{array}{l}-0.061 \\
(0.027)\end{array}$ & $\begin{array}{l}-0.076 \\
(0.038)\end{array}$ & $\begin{array}{l}-0.079 \\
(0.038)\end{array}$ \\
\hline $\begin{array}{l}\text { 1974-1984 Period } \\
\text { Dummy }\end{array}$ & & $\begin{array}{c}0.201 \\
(0.131)\end{array}$ & $\begin{array}{c}0.264 \\
(0.133)\end{array}$ & $\begin{array}{l}-0.166 \\
(0.171)\end{array}$ & $\begin{array}{l}-0.125 \\
(0.174)\end{array}$ \\
\hline $\begin{array}{l}\text { Transfer Agent Overall } \\
\text { Market Share }\end{array}$ & & & $\begin{array}{l}-0.038 \\
(0.011)\end{array}$ & $\begin{array}{l}-0.009 \\
(0.013)\end{array}$ & $\begin{array}{l}-0.012 \\
(0.013)\end{array}$ \\
\hline $\begin{array}{l}\text { Proportion of Assets } \\
\text { with Custodian }\end{array}$ & & & & $\begin{array}{l}-0.005 \\
(0.003)\end{array}$ & $\begin{array}{l}-0.005 \\
(0.003)\end{array}$ \\
\hline $\begin{array}{l}\text { Proportion of Funds } \\
\text { with Custodian }\end{array}$ & & & & $\begin{array}{c}0.004 \\
(0.003)\end{array}$ & $\begin{array}{c}0.003 \\
(0.003)\end{array}$ \\
\hline $\begin{array}{l}\text { Duration of Fund Transfer } \\
\text { Agent Relationship }\end{array}$ & & & & $\begin{array}{c}-0.017 \\
(0.017)\end{array}$ & $\begin{array}{l}-0.018 \\
(0.017)\end{array}$ \\
\hline Common State & & & & $\begin{array}{l}-0.802 \\
(0.165)\end{array}$ & $\begin{array}{l}-0.837 \\
(0.167)\end{array}$ \\
\hline Switch Distributor & & & & $\begin{array}{c}0.412 \\
(0.206)\end{array}$ & $\begin{array}{c}0.410 \\
(0.207)\end{array}$ \\
\hline Non-Bank & & & & & $\begin{array}{l}-0.345 \\
(0.237)\end{array}$ \\
\hline Observations & 1906 & 1906 & 1906 & 1327 & 1327 \\
\hline Parameters & 1 & 4 & 5 & 10 & 11 \\
\hline$G^{2}$ & 1715.392 & 1703.409 & $1690.566^{a}$ & 1155.789 & 1153.579 \\
\hline \multirow[t]{2}{*}{ Difference in $\mathrm{G}^{2}$} & \multicolumn{2}{|c|}{11.982} & \multicolumn{2}{|c|}{85.69} & .21 \\
\hline & \multicolumn{2}{|c|}{$p<.01$} & \multicolumn{2}{|c|}{$p<.001$} & 10 \\
\hline
\end{tabular}

a The value of $\mathrm{G}^{2}$ for a $\mathrm{N}$ of 1304 observations is 1191.474 
Table 3

Multinomial Analysis of Custodian Choice

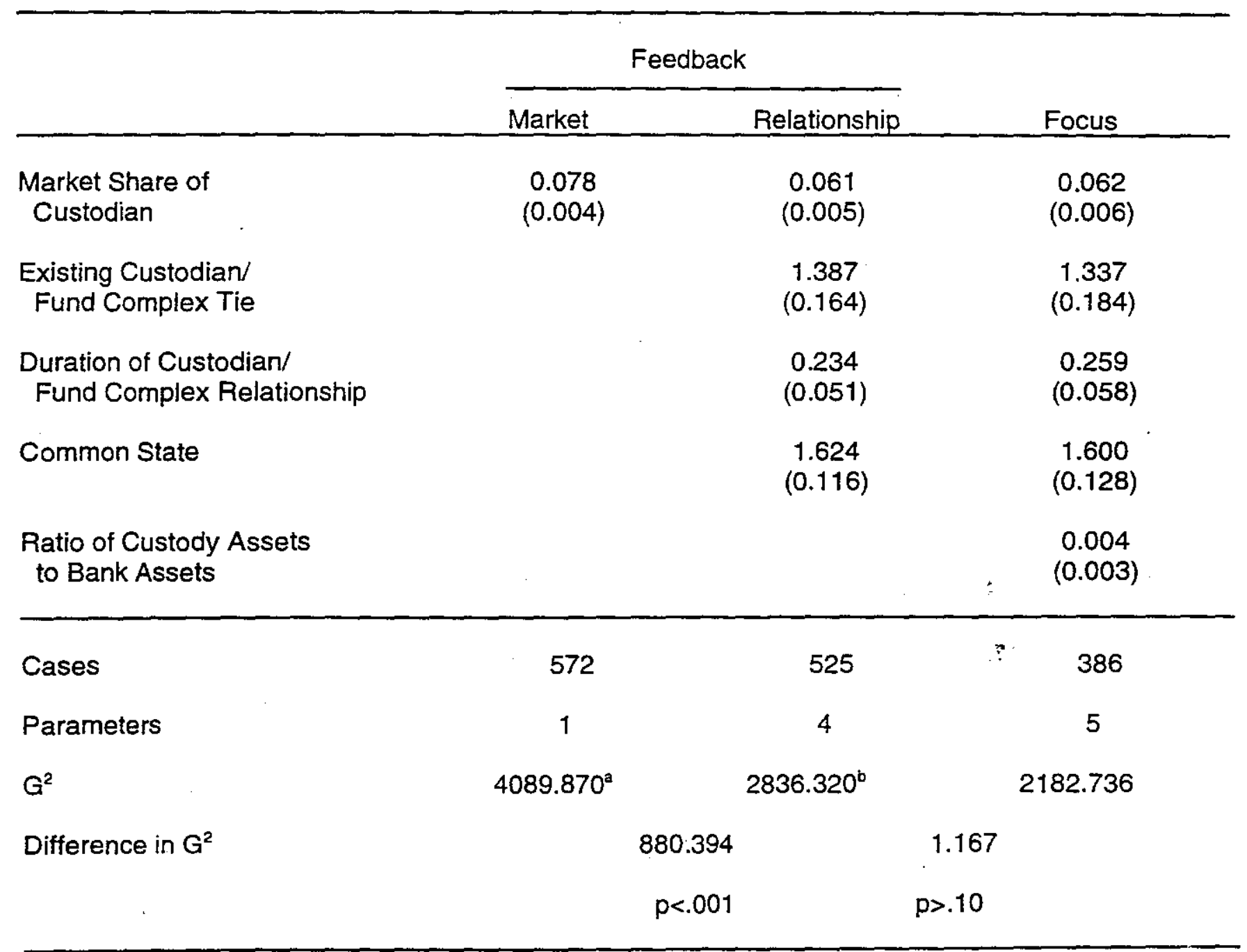

The value of $G^{2}$ for a $N$ of 525 is 3716.714

b The value of $G^{2}$ for a $N$ of 386 is 2183.903 
Table 4

Multinomial Analysis of Transfer Agent Choice

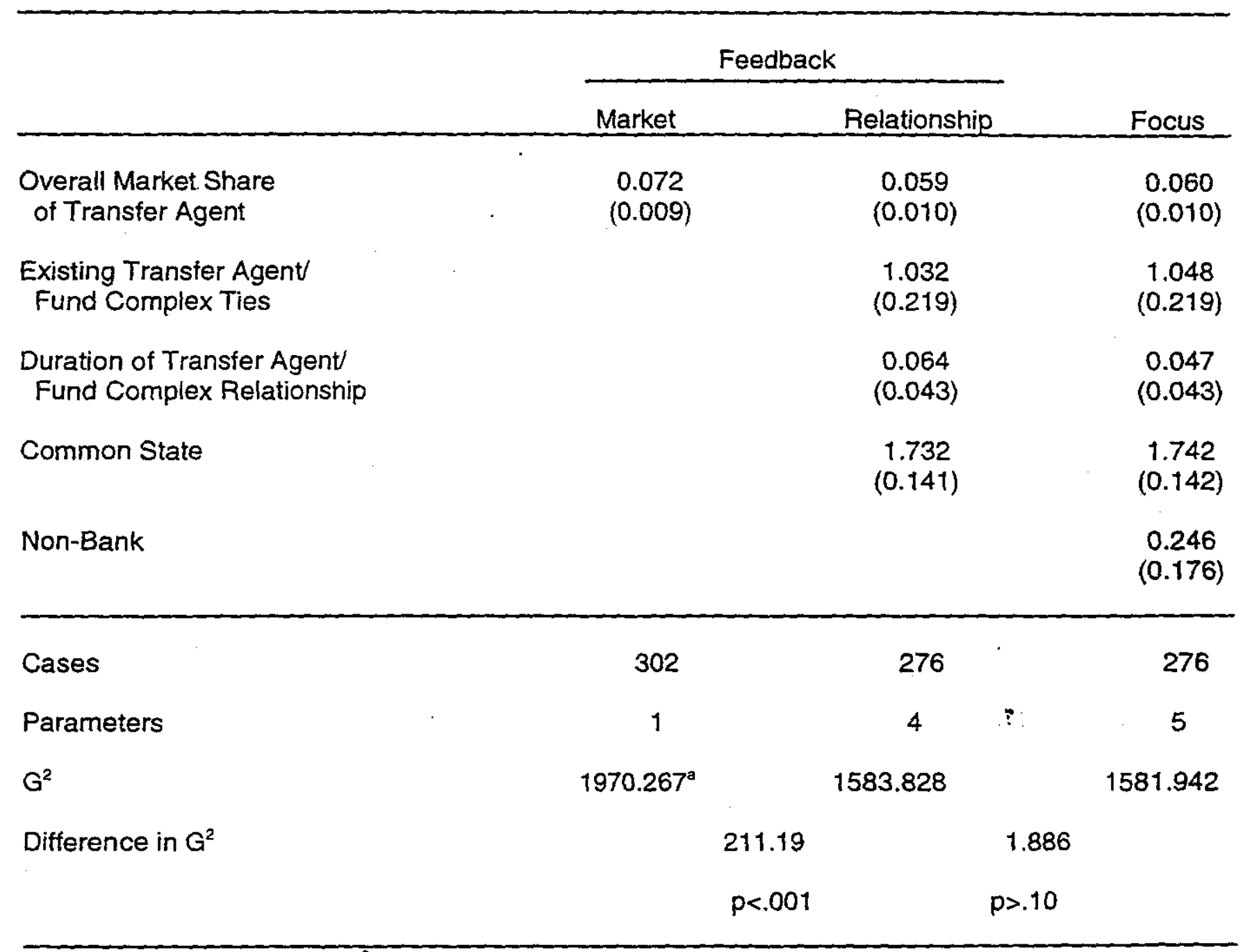

a The market model has a $\mathrm{G}^{2}$ value of 1795.015 for 276 cases. 


.

